\title{
Ion Insertion Into Individual 7,7,8,8-Tetracyanoquinodimethane
}

\section{Nanoparticles}

\author{
XF Zhou, W Cheng, R G. Compton* \\ Department of Chemistry, Physical \& Theoretical Chemistry Laboratory, Oxford University, South Parks Road, \\ Oxford, OX1 3QZ, United Kingdom \\ Fax: (+44) 1865-275-410, Corresponding email: richard.compton@chem.ox.ac.uk
}

\begin{abstract}
We report the quantification of partial ion insertion into individual 7,7,8,8tetracyanoquinodimethane nanoparticles. It is shown that both potassium and sodium ions can be inserted into single TCNQ nanoparticles from aqueous solution. The extent of both potassium and sodium insertion into individual nanoparticles is quantitatively measured and shown to be partial and sodium ion shows a higher extent of insertion. The insertion process is inferred to be limited and controlled by the formation of a thin shell of salt, $\mathrm{Na}^{+} / \mathrm{K}^{+} \mathrm{TCNQ}-$ formed at the surface of the nanoparticle.
\end{abstract}




\section{Introduction}

Ion extraction and insertion is a central process in energy transformation using batteries and fuel cells. The improved electron/ion transport due to superior contact between electrolyte solutions makes micro/nanostructures and nanoparticles attractive as electrode materials for lithium or sodium ion batteries ${ }^{1,2}$. Studying the extraction and insertion of ions is challenging, because the charge transfer is strongly coupled to mass transport processes which typically can only be approximately quantified when using an ensemble of nanoparticles supported on an electrode surface. To date, the real-time characterisation and quantification of ion insertion into single nanoparticles has not been possible ${ }^{3}$ although currently there are rapidly increasing applications using nanostructured/nanoparticles anodes for lithium ion storage ${ }^{4,5}$.

As concern rises for the toxicity and limited natural resources of lithium, sodium or potassium ion batteries (SIBs or KLBs) as an alternative to lithium ions batteries have recently attracted significant attention ${ }^{6,7}$. However, the mechanism of $\mathrm{Na}$ or $\mathrm{K}$ ion transport into nanostructured materials at nanoscale has been rarely experimentally explored. The quantitative analysis of such ion insertion is important to understand the underlying mechanism of different cations insertion ${ }^{8}$ and to the rational design of intermolecular structures of electrodes for ideal battery performance ${ }^{9}$.

The method of "nano impacts" has been recently developed to study single nanoparticle events as a result of their random collision with an electrode as a consequence of their Brownian motion. If the electrode is held at a suitable potential this can induce oxidation/reduction of, or catalytic reaction by, the nanoparticle ${ }^{10-23}$. In this report, using 
$7,7^{\prime}, 8,8^{\prime}$-tetracyanoquinodimethane(TCNQ) nanoparticles in aqueous solution as a model, we report ion insertion into single nanoparticles. The quantification of the cation insertion at the single nanoparticle level is established and a limiting mechansim proposed.

TCNQ is a well-known organic charge-transfer salt that has a well-defined quasi-onedimensional structure with a high electronic conductivity ${ }^{24}$ and has been recently used as a new organic nanomaterial-based electrode $^{20}$ which builds on traditional inorganic nanomaterials for possible future large-scale applications ${ }^{9,25}$. TCNQ has previously been characterised by modifying the electrode with the ensemble of TCNQ microcrystals immobilised on an electrode surface ${ }^{26,27}$ or studying the chemical reactions occurring in TCNQ micro/nanoparticles ${ }^{28,29}$. In this article, the potassium and sodium insertion into single TCNQ nanoparticles has been quantitatively analysed at single nanoparticle level, showing a higher extent of insertion for sodium ions, and a thin layer limiting mechanism was proposed with the formation of a thin shell of salt, $\mathrm{Na}^{+} / \mathrm{K}^{+} \mathrm{TCNQ}-$ formed on the surface of the nanoparticle, whilst the thickness of shell is independent on the nanoparticle size but does reflect the cation type. 


\section{Experimental}

\section{Chemicals}

7,7,8,8-Tetracyanoquinodimethane (TCNQ, 98\%) was purchased from Sigma-Aldrich. Dimethyl sulfoxide (DMSO, $\geq 99.7 \%$ ) was obtained from Fisher Scientific and used as received. The phosphate buffer solution $(\mathrm{pH}=6.8)$ containing only $\mathrm{K}^{+}$was composed of 50 $\mathrm{mM}$ monobasic and dibasic potassium phosphates; $0.1 \mathrm{M} \mathrm{KCl}$ used as further supporting electrolyte. The phosphate buffer solution $(\mathrm{pH}=6.8)$ containing only $\mathrm{Na}^{+}$was composed of $50 \mathrm{mM}$ monobasic and dibasic sodium phosphates; $0.1 \mathrm{M} \mathrm{NaCl}$ has again used as further supporting electrolyte. All solutions were made up with deionised water of resistivity not less than 18.2 M $\Omega \mathrm{cm}$ (Millipore) at $298 \mathrm{~K}$ and degassed with nitrogen (oxygen-free, BOC Gases plc) before use.

\section{Synthesis and characterization of TCNQ nanoparticles}

TCNQ nanoparticles were synthesised using the reprecipitation method ${ }^{30}$. To prepare different sizes of nanoparticles, $5 \mathrm{mM}$ or $10 \mathrm{mM}$ TCNQ/DMSO solutions were added into 10 $\mathrm{mL}$ deionised water under vigorously stirring by magnetic vortexing at $800 \mathrm{rpm}$. Then they were subjected to sonication for $10 \mathrm{~min}$ at room temperature. Dynamic light scattering (DLS, Malvern Instruments Ltd, UK) measurements were performed to characterize the size distribution of the synthesised TCNQ nanoparticles. Scanning electron microscopy (SEM) was carried out on a glassy carbon wafer with a Jeol 6480L SEM (Jeol, Japan) operating at 5 $\mathrm{kV}$ to study the shape of the TCNQ particles dispersed in Milli-Q water (100 times diluted from the stock suspension). 


\section{Electrochemical characterization of TCNQ nanoparticles}

Electrochemical experiments were conducted at $25^{\circ} \mathrm{C}$ with a double Faraday cage with a three electrode system using an Autolab II potentiostat (Metrohm-Autolab BV, Netherlands). For cyclic voltammetry measurements, a glassy carbon macroelectrode (GC, diameter $3.0 \mathrm{~mm}$ ) was used as the working electrode, a saturated calomel electrode (SCE) as the reference electrode and a carbon rod acted as a counter electrode. The GC macroelectrode was modified by dropping varying amounts of the TCNQ NPs suspension onto the surface and letting the electrode dry under nitrogen. Cyclic voltammetry was conducted at a scan rate of $50 \mathrm{mV} / \mathrm{s}$ in $0.1 \mathrm{M} \mathrm{K}^{+}$or $\mathrm{Na}^{+}$PBS buffer, $0.1 \mathrm{M} \mathrm{KCl}, 0.1 \mathrm{M} \mathrm{NaCl}$ and $0.1 \mathrm{M} \mathrm{HCl}$. All solutions were degassed thoroughly with nitrogen before scanning. Working electrodes were polished with three grades of diamond spray $(3,1$ and 0.1 microns) before sonication in water and drying with nitrogen prior to each scan.

\section{Ion insertion into single TCNQ nanoparticles}

For the electrochemical study of single TCNQ nanoparticles, chronoamperometry was performed with a carbon microelectrode (diameter $=10 \mu \mathrm{m}$ ) as working electrode and the same reference and counter electrodes as used for macroelectrode experiments in $0.1 \mathrm{M}$ PBS buffer with a known concentration of TCNQ nanoparticles solution (32 pM) added. The carbon micro electrode diameter was calibrated electrochemically by analysing the steady state voltammetry of a $2.0 \mathrm{mM}$ ferrocene in acetonitrile containing $0.1 \mathrm{M}$ TBAP, using a diffusion coefficient for ferrocene of $2.30 \times 10^{-9} \mathrm{~m}^{2} \mathrm{~s}^{-1}$ at $298 \mathrm{~K}^{31}$. The Software "Signal 
Counter" (developed by Dr. D Omanović, Center for Marine and Environmental Research Zagreb, Croatia) was used for analysis of the impact spikes observed and OriginPro 9 for statistical analysis of the charge passed per spike.

\section{Results and Discussion}

\section{Cyclic voltammograms of ensembles of TCNQ nanoparticles}

Two sizes of TCNQ nanoparticles (with diameters of $71 \mathrm{~nm}$ and $116 \mathrm{~nm}$, Figure S1) were synthesised using the reprecipitation method ${ }^{29}$. The SEM of TCNQ nanoparticles were shown in Figure 1.

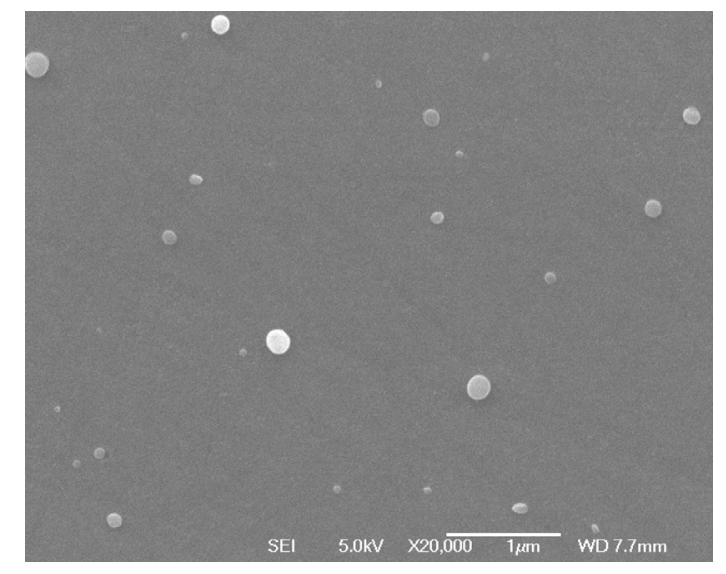

(a)

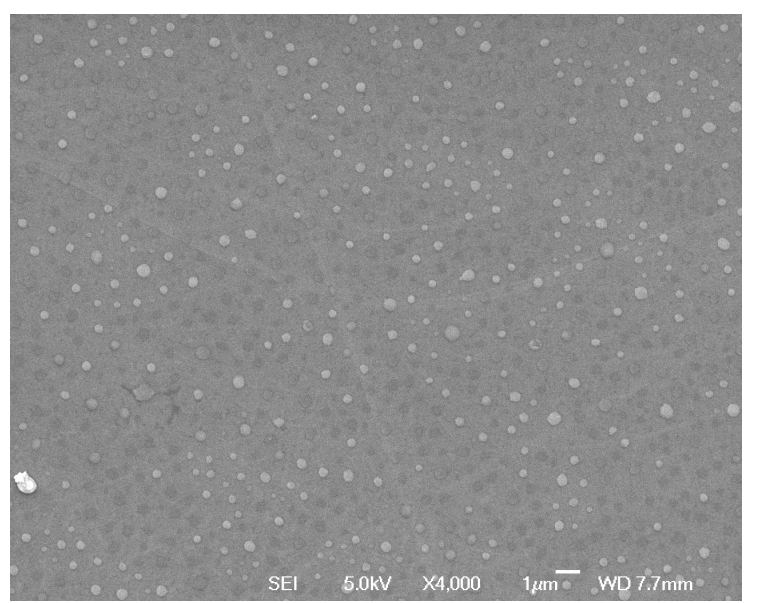

(b)

Figure 1 (a) SEM images of the synthesised small TCNQ (a) and large TCNQ (b) nanoparticles. 
Before studying single TCNQ nanoparticles, the electrochemical behaviour of ensembles of TCNQ nanoparticles were investigated. First, a macro glassy carbon (GC) electrode (diameter $=3 \mathrm{~mm}$ ) was modified with different amounts of TCNQ nanoparticles and cyclic voltammograms recorded. Figure 1 shows the cyclic voltammograms recorded for a glassy carbon macroelectrode modified with various loadings of TCNQ nanoparticles of two sizes immersed in phosphate buffered saline (PBS) buffer $(\mathrm{pH}=6.8)$ containing either only $\mathrm{K}^{+}$as cation $\left(\mathrm{K}^{+}\right.$buffer), or only $\mathrm{Na}^{+}$as cation $\left(\mathrm{Na}^{+}\right.$buffer). In $\mathrm{K}^{+}$buffer, a reduction peak potential at $-0.03 \mathrm{~V}$ and an oxidation peak potential at $+0.25 \mathrm{~V}$ versus the saturated calomel reference electrode (SCE) likely correspond to one-electron transfer between TCNQ and TCNQ*-

$$
\mathrm{K}^{+}+\mathrm{TCNQ}+\mathrm{e}^{-} \rightleftharpoons \mathrm{K}^{+} \mathrm{TCNQ}^{-}
$$

consistent with previous reports ${ }^{32,33}$. An inert zone exists which is characteristic of ion insertion between the two peaks also observed in $\mathrm{Na}^{+}$buffer with a reduction peak potential at $-0.05 \mathrm{~V}$ and oxidation peak potential at $+0.28 \mathrm{~V}$, corresponding to the reaction:

$$
\mathrm{Na}^{+}+\mathrm{TCNQ}+\mathrm{e}^{-} \rightleftharpoons \mathrm{Na}^{+} \mathrm{TCNQ}^{-}
$$

The voltammetric peaks decay when the potential is cycled. The reductive charge is therefore estimated from the reduction peak of the first scans for all loadings of TCNQ nanoparticles. The peak charge was found to linearly increase with the TCNQ nanoparticle loadings on the electrode surface (Figure 2), and the total reductive charge likely reflect the state of agglomeration/aggregation of nanoparticles where only the nanoparticles at the periphery of the aggregated particles that are in contact with the electrode are reduced ${ }^{34}$, and the overlapping of adjacent diffusion layers ${ }^{35}$, as well as the charge insertion into individual TCNQ nanoparticles. 


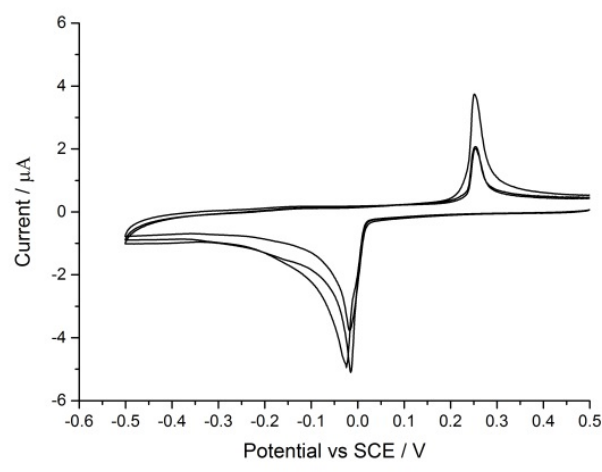

(a)

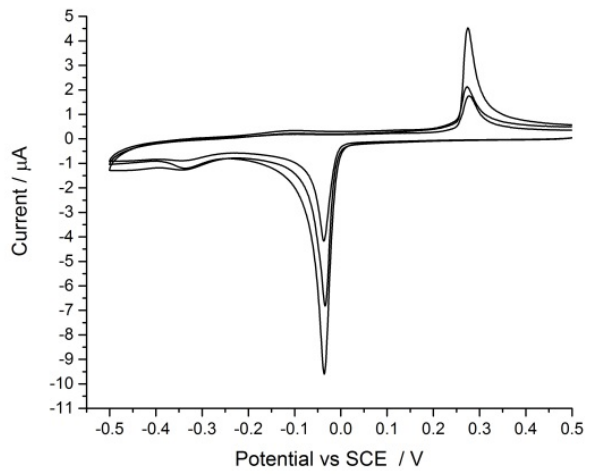

(c)

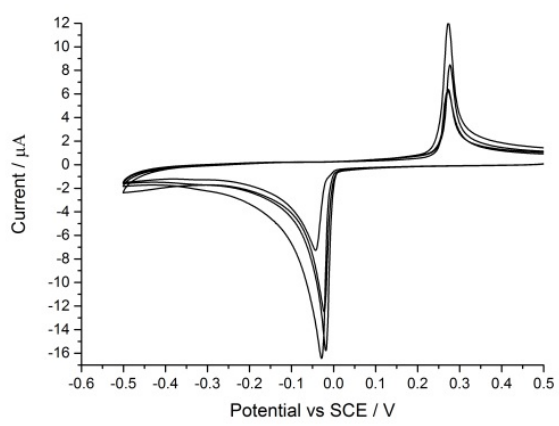

(b)

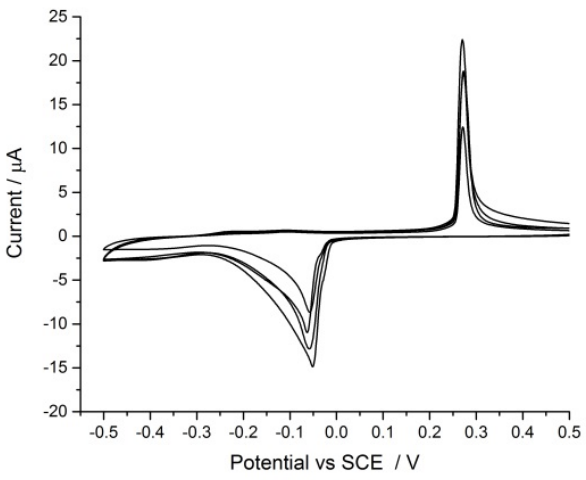

(d)

Figure 1 Cyclic voltammograms (the first cycle) recorded for a glassy carbon macroelectrode modified with various loading of TCNQ nanoparticles of two sizes in $0.1 \mathrm{M}$ PBS buffer solution containing only $\mathrm{K}^{+}$or $\mathrm{Na}^{+}$as cation at a scan rate of $50 \mathrm{mV} / \mathrm{s}$ : (a) various amounts of $71 \mathrm{~nm}$ TCNQ nanoparticles (monomer moles): $1 \times 10^{-10}$ mol, $1.5 \times 10^{-10} \mathrm{~mol}, 2 \times 10^{-10} \mathrm{~mol}$ in $\mathrm{K}^{+}$buffer (b) various amounts of $116 \mathrm{~nm}$ TCNQ nanoparticles (monomer moles): $2 \times 10^{-10} \mathrm{~mol}, 3 \times 10^{-10} \mathrm{~mol}, 4 \times 10^{-10} \mathrm{~mol}, 5 \times 10^{-10} \mathrm{~mol}$ in $\mathrm{K}^{+}$buffer (c) various amount of $71 \mathrm{~nm}$ TCNQ nanoparticles (monomer moles): $2 \times 10^{-10} \mathrm{~mol}, 3 \times 10^{-10} \mathrm{~mol}, 4 \times 10^{-10} \mathrm{~mol}$ in $\mathrm{Na}^{+}$buffer (d) various amount of 116 nm TCNQ nanoparticles (monomer moles): $2 \times 10^{-10} \mathrm{~mol}, 3 \times 10^{-10} \mathrm{~mol}, 4 \times 10^{-10} \mathrm{~mol}, 5 \times 10^{-10} \mathrm{~mol}$ in $\mathrm{Na}^{+}$buffer. 


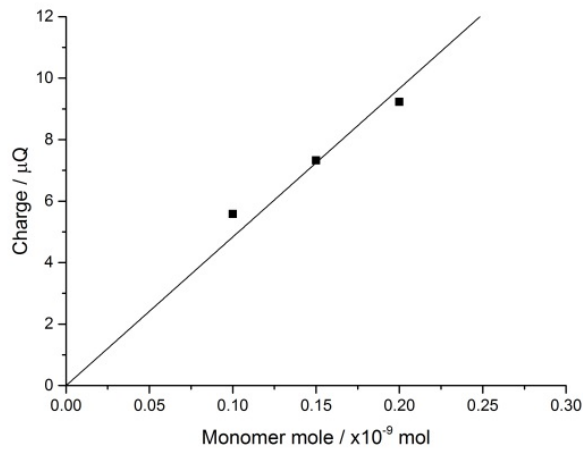

(a)

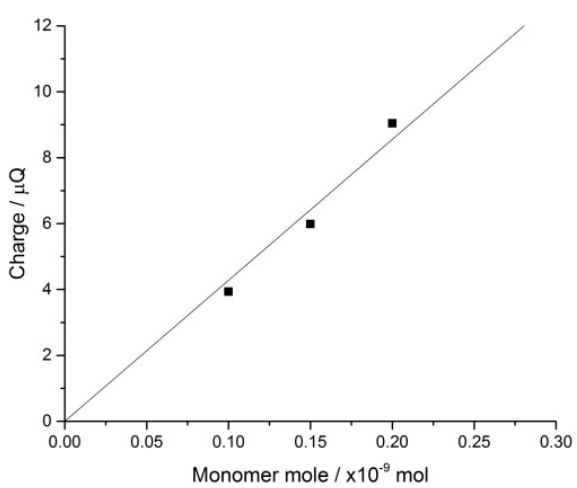

(b)

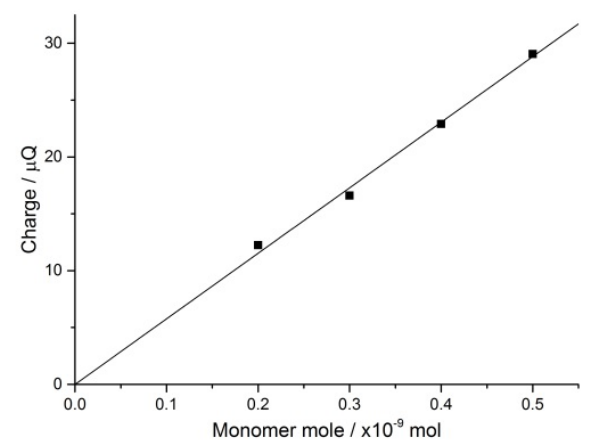

(b)

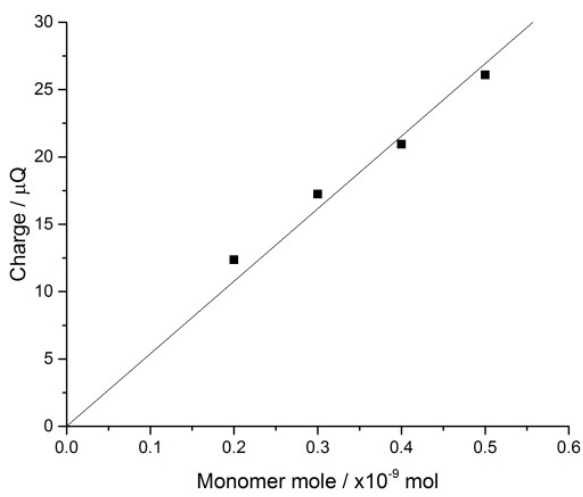

(d)

Figure 2 Linear relation between the cathodic peak charges (obtained from the integration of the peak area from Figure 1) and the TCNQ nanoparticle loadings on the electrode surface (a) $71 \mathrm{~nm}$ TCNQ nanoparticles modified electrode in $\mathrm{K}^{+}$buffer (b) $116 \mathrm{~nm}$ TCNQ nanoparticles modified electrode in $\mathrm{K}^{+}$buffer (c) $71 \mathrm{~nm}$ TCNQ nanoparticles modified electrode in $\mathrm{Na}^{+}$buffer (d) $116 \mathrm{~nm}$ TCNQ nanoparticles modified electrode in $\mathrm{Na}^{+}$ buffer.

Cyclic voltammograms of TCNQ nanoparticles modified GC electrode were also conducted in hydrochloric acid, sodium chloride, and potassium chloride (Figure 3). The reduction of TCNQ nanoparticles shows a chemically reversible process in $0.1 \mathrm{M} \mathrm{KCl}$, with a reduction peak potential seen at $-0.03 \mathrm{~V}$ and at oxidation peak potential at $+0.25 \mathrm{~V}$. The voltammogram is similar to that observed in $0.1 \mathrm{M}$ PBS buffer only containing $\mathrm{K}^{+}$as cation. A similar chemically reversible process was also recorded in $0.1 \mathrm{M} \mathrm{NaCl}$ with a reduction peak potential at $-0.05 \mathrm{~V}$ and similar voltammogram to $0.1 \mathrm{M}$ PBS buffer containing only $\mathrm{Na}^{+}$as 
cation. The reduction of TCNQ nanoparticles in both $0.1 \mathrm{M} \mathrm{KCl}$ and $0.1 \mathrm{M} \mathrm{NaCl}$ are in contrast to that in $0.1 \mathrm{M} \mathrm{HCl}$, where no reduction peak was seen inside the potential range from $-0.5 \mathrm{~V}$ to $0.5 \mathrm{~V}$, indicating that potassium or sodium ions insertion must accompany the reduction of TCNQ nanoparticles as shown in Scheme 1.

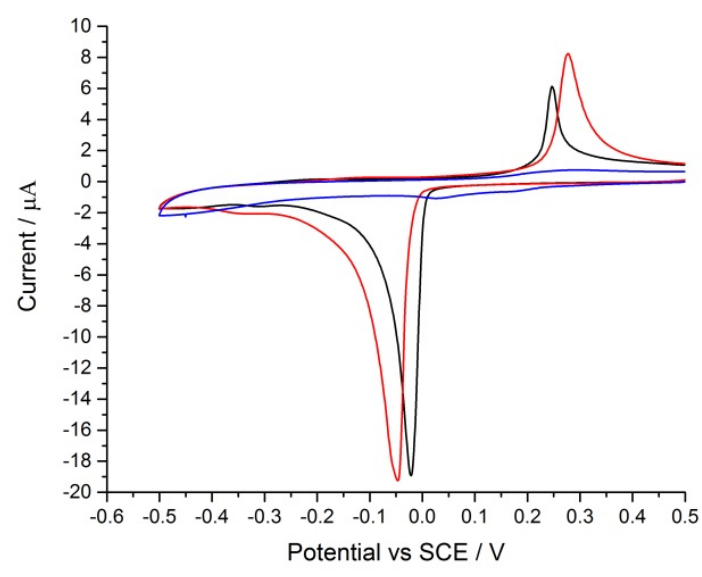

Figure 3 Cyclic voltammograms recorded for a glassy carbon macroelectrode modified with $4 \times 10^{-10}$ mol (monomer mole) TCNQ nanoparticles (diameter: $116 \mathrm{~nm}$ ) in $0.1 \mathrm{M} \mathrm{KCl}$ (black), $0.1 \mathrm{M} \mathrm{NaCl}$ (red) and $0.1 \mathrm{M}$ $\mathrm{HCl}$ (blue) at a scan rate of $50 \mathrm{mV} / \mathrm{s}$

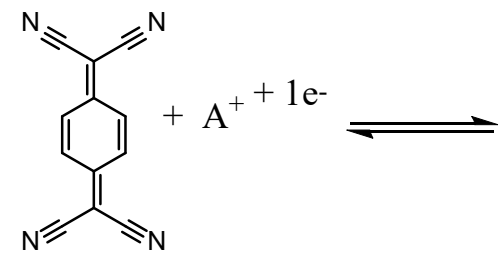<smiles>N#CCC1C=CC(=C(C#N)C#N)C=C1</smiles>

$$
\mathrm{A}^{+}: \mathrm{K}^{+} \text {or } \mathrm{Na}_{+}
$$

Scheme 1 


\section{Nano-impacts of individual TCNQ nanoparticles}

To study the reduction of individual TCNQ nanoparticles, a carbon microelectrode was immersed in a PBS buffer $(\mathrm{pH}=6.8)$ solution containing either only $\mathrm{K}^{+}$as cation (other than protons) or only $\mathrm{Na}^{+}$as cation and known concentrations of a TCNQ nanoparticle suspension (32 $\mathrm{pM}$ ) added. The reduction potential was selected to be $-0.3 \mathrm{~V}$ for chronoamperometric measurements of individual TCNQ nanoparticle collisions with the electrode, as recorded by current spikes in the current-time response, with each spike representing a single impact, as shown in Figure 4.

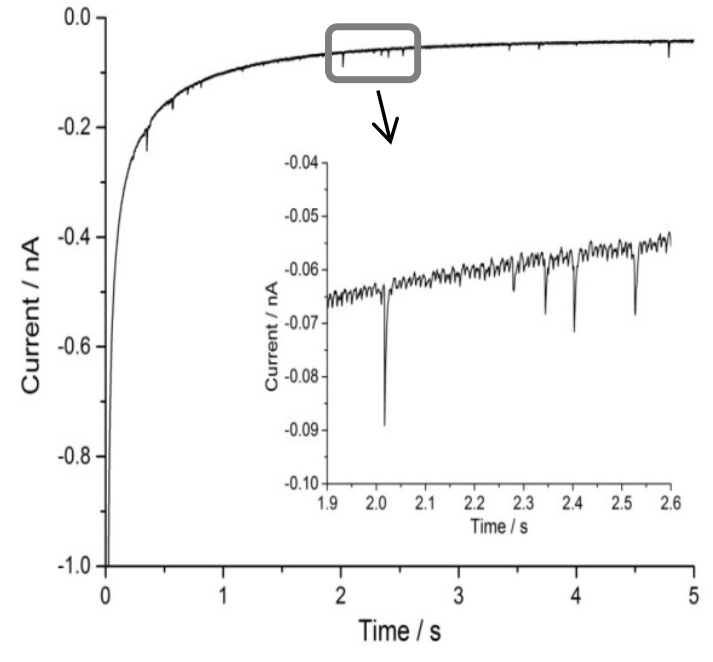

(a)

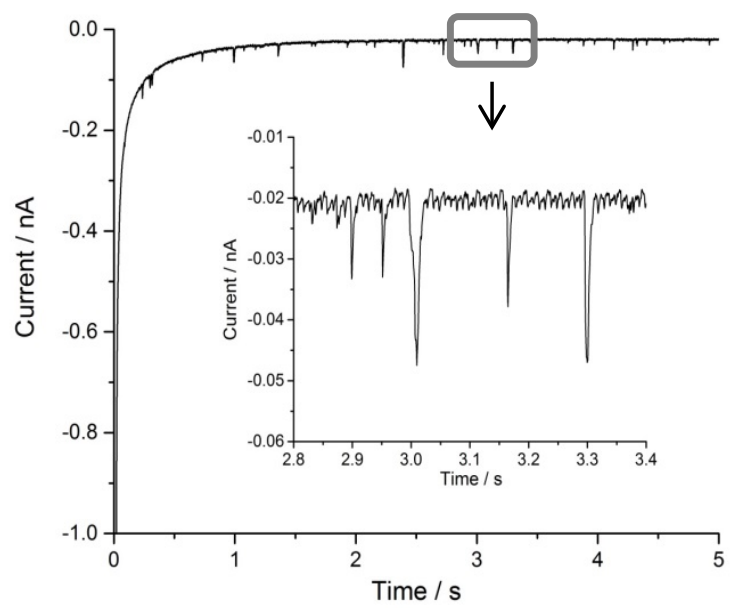

(c)

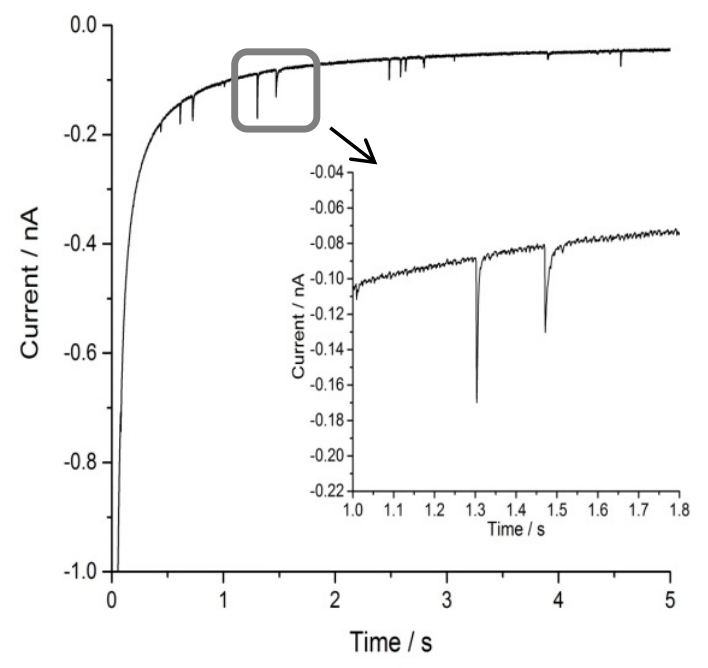

(b)

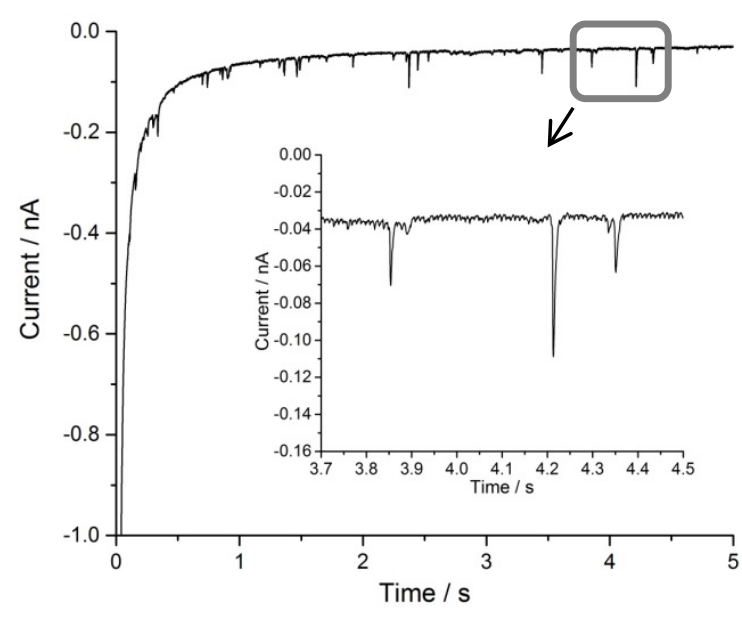

(d) 
Figure 4 Chronoamperometric profiles showing reductive Faradaic spikes of (a) $71 \mathrm{~nm}$ and (b) $116 \mathrm{~nm}$ TCNQ nanoparticles at $-0.30 \mathrm{~V}$ vs. SCE. in $\mathrm{K}^{+} \mathrm{PBS}$ buffer $(\mathrm{pH}=6.8$ ), and (c) $71 \mathrm{~nm}$ and (d) $116 \mathrm{~nm}$ TCNQ nanoparticles at $-0.30 \mathrm{~V}$ vs. SCE. in $\mathrm{Na}^{+}$PBS buffer $(\mathrm{pH}=6.8)$. The inset showing the detailed impact spikes.

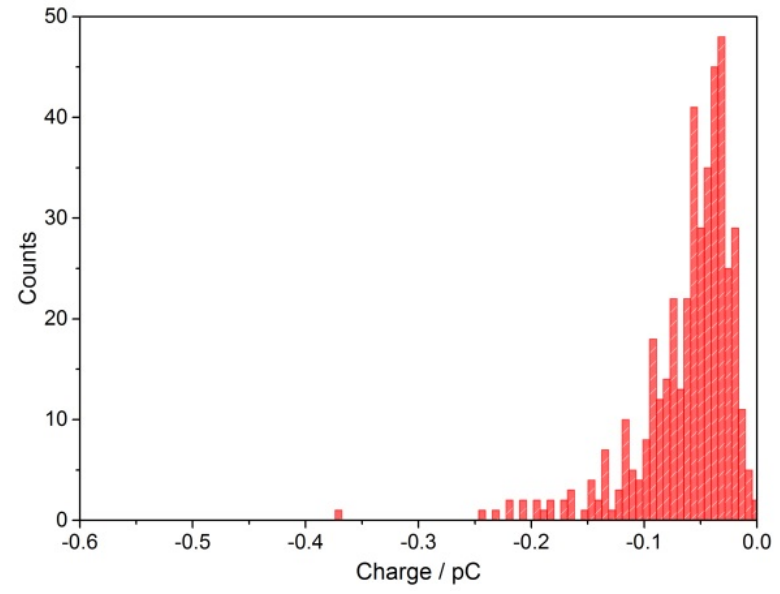

(a)

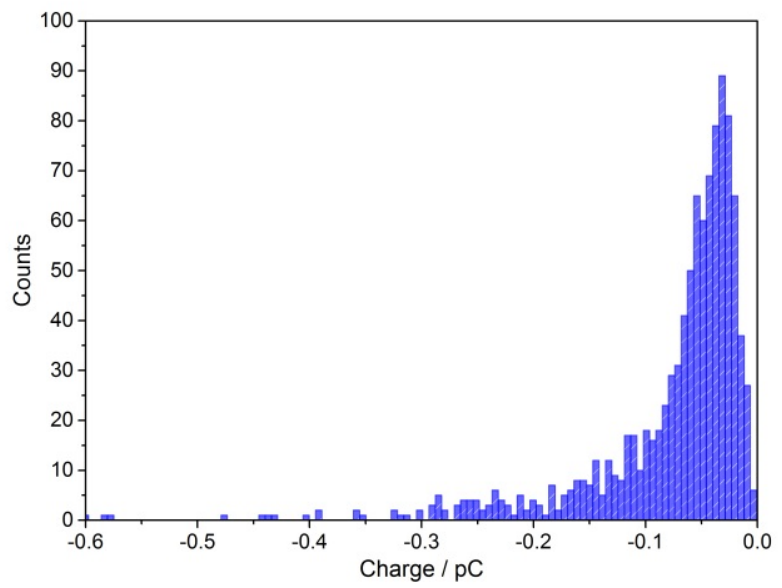

(c)

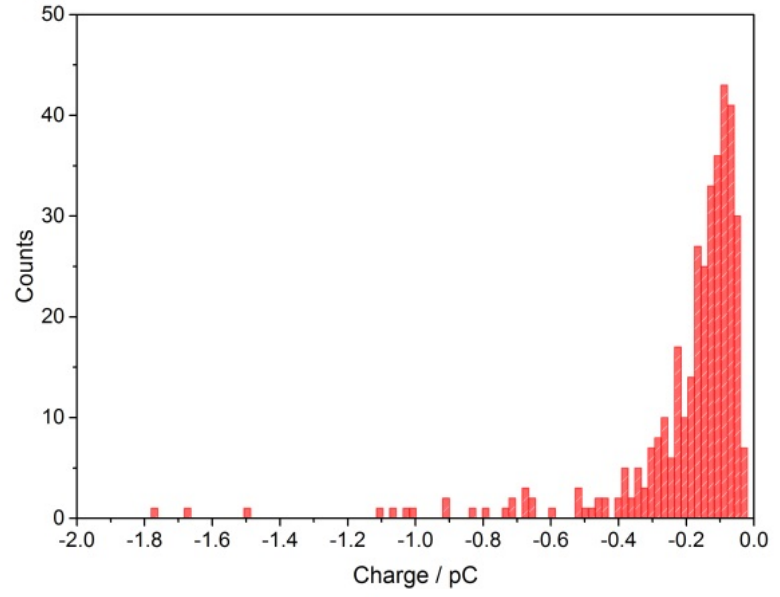

(b)

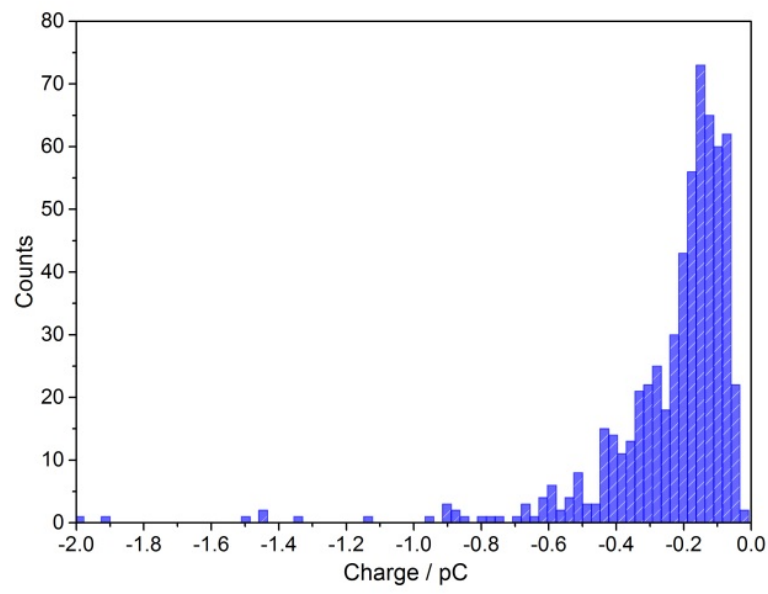

(d)

Figure 5 Histograms of the reductive charge resulting from ion insertion into individual TCNQ nanoparticles in PBS buffer $(\mathrm{pH}=6.8)$ at $-0.30 \mathrm{~V}$ vs. SCE. (a) $71 \mathrm{~nm}$ nanoparticles in $\mathrm{K}^{+}$PBS buffer $(\mathrm{pH}=6.8)$, with average charge $\mathrm{Q}_{\mathrm{K} 1}=6.10 \times 10^{-14} \mathrm{C}$ from 433 individual spikes; (b) $116 \mathrm{~nm}$ nanoparticles in $\mathrm{K}^{+} \mathrm{PBS}$ buffer $(\mathrm{pH}=6.8)$, with average charge $\mathrm{Q}_{\mathrm{K} 2}=1.96 \times 10^{-13} \mathrm{C}$ from 360 individual spikes; (c) $71 \mathrm{~nm}$ nanoparticles in $\mathrm{Na}^{+} \mathrm{PBS}$ buffer $(\mathrm{pH}=6.8)$, with average charge $\mathrm{Q}_{\mathrm{Na} 1}=7.71 \times 10^{-14} \mathrm{C}$ from 1019 individual spikes; (d) $116 \mathrm{~nm}$ nanoparticles in $\mathrm{Na}^{+}$PBS buffer $(\mathrm{pH}=6.8)$, with average charge $\mathrm{Q}_{\mathrm{Na} 2}=2.38 \times 10^{-13} \mathrm{C}$ from 605 individual spikes. 
No reductive spikes at potentials of $0 \mathrm{~V}$ or more positive were observed, suggesting the monitored spikes only correspond to potassium or sodium insertion accompanying Faradaic reduction of TCNQ nanoparticles. Another control experiment was conducted at the potential of $-0.30 \mathrm{~V}$ with no TCNQ nanoparticles in the solution and again no spikes were detected, further suggesting that the occurrence of reductive spikes is due to the random collisions of TCNQ nanoparticles with the electrode. The charge from ion insertion into individual TCNQ nanoparticles was then calculated by integrating the area of each spike (Figure 5).

\section{Quantification of potassium and sodium insertion into individual TCNQ nanoparticles}

To quantify ion insertion into TCNQ nanoparticles, the mean diameters (Dnp) of the two batches of TCNQ nanoparticles was estimated to be $71 \mathrm{~nm}$ and $116 \mathrm{~nm}$ through dynamic light scattering (Figure S1). If the charge is passed as a result of complete $(100 \%)$ ion insertion of single TCNQ nanoparticles, then the ideal charge $(Q i)$ of electron transfer from ion insertion of single TCNQ nanoparticles can be determined by Equation 1, assuming that TCNQ nanoparticles are spherical (The SEM images of TCNQ nanoparticles were shown in Figure 1) .

$$
Q i=\frac{D_{n p}{ }^{3} n F \pi \rho}{6 M}
$$

Equation 1

where Dnp is the diameter of TCNQ nanoparticles, M is the molar mass of TCNQ, $\rho$ is the density of TCNQ and F is the Faraday constant. The parameter $\mathrm{n}$ is the number of electrons transferred per molecule during ion insertion into nanoparticles, where $\mathrm{n}=1$ for TCNQ reduction to TCNQ- 
By comparing the average reductive charge $Q_{r}$ resulting from ion insertion into all the measured individual TCNQ nanoparticles (Figure 5) with a diameter of $71 \mathrm{~nm}$ or $116 \mathrm{~nm}$ from experimental nano-impacts against the ideal charge $Q i$ assuming the complete ion insertion $\left(Q_{i 1}=1.24 \times 10^{-13} \mathrm{C}\right.$ for single $71 \mathrm{~nm}$ TCNQ nanoparticles or $Q_{i 2}=5.48 \times 10^{-13} \mathrm{C}$ for single $116 \mathrm{~nm}$ TCNQ nanoparticles, according to Equation 1), the yield of ion insertion into single TCNQ nanoparticle $\left(y=Q_{r} / Q i\right)$ can be determined. Specifically, as for potassium insertion into single TCNQ nanoparticles of $71 \mathrm{~nm}$, we calculated the average charge resulting from all individual spikes to be $6.10 \times 10^{-14} \mathrm{C}$ (Figure $5 \mathrm{a}$ ), and the potassium insertion yield to be $49 \%$. The charge is found to be potential-independent (the same value was observed at $-0.2 \mathrm{~V}$ as at $-0.3 \mathrm{~V}$, Figure S2), suggesting that a maximum yield of ion insertion is realised.

Further, considering there is a size distribution of TCNQ nanoparticles, the distributions of charge from ion insertion into a single nanoparticle of both $71 \mathrm{~nm}$ and $116 \mathrm{~nm}$ TCNQ NPs (Figure 6) were plotted for both potassium and sodium insertion. We found there were good agreements between the distribution of charge from ion insertion into a single nanoparticle, as analysed for single TCNQ nanoparticles and the theoretical estimation, although some discrepancy is seen for large particles. This is because large nanoparticles have a lower diffusion coefficient, which leads to a lower probability of observing impacts ${ }^{35}$. The yield of ion insertion into single TCNQ nanoparticle $(y)$ is estimated as $49 \%\left(y_{K 1}\right)$, and $36 \%\left(y_{K 2}\right)$, respectively for potassium insertion into $71 \mathrm{~nm}$ and $116 \mathrm{~nm}$ TCNQ NPs, and 62\% ( $\left.y_{\text {Nal }}\right)$, and $43 \%\left(y_{N a 2}\right)$, respectively for sodium insertion into $71 \mathrm{~nm}$ and $116 \mathrm{~nm}$ TCNQ NPs (the yield values were derived according to Equation 1). To our knowledge, this is the first time that the quantitative determination of the extent of cation insertion at the single nanoparticle level has been demonstrated. The charge injection into individual nanoparticles is similar to that of 
TCNQ nanoparticles immobilised on the electrode, where the ratio of charge from partial reduction of TCNQ is $60 \%$ and $50 \%$, in $\mathrm{K}^{+}$PBS buffer, $56 \%$ and $45 \%$ in $\mathrm{Na}^{+}$PBS buffer, respectively for $71 \mathrm{~nm}$ and $116 \mathrm{~nm}$, and may be limited by short impact times (Figure S3).

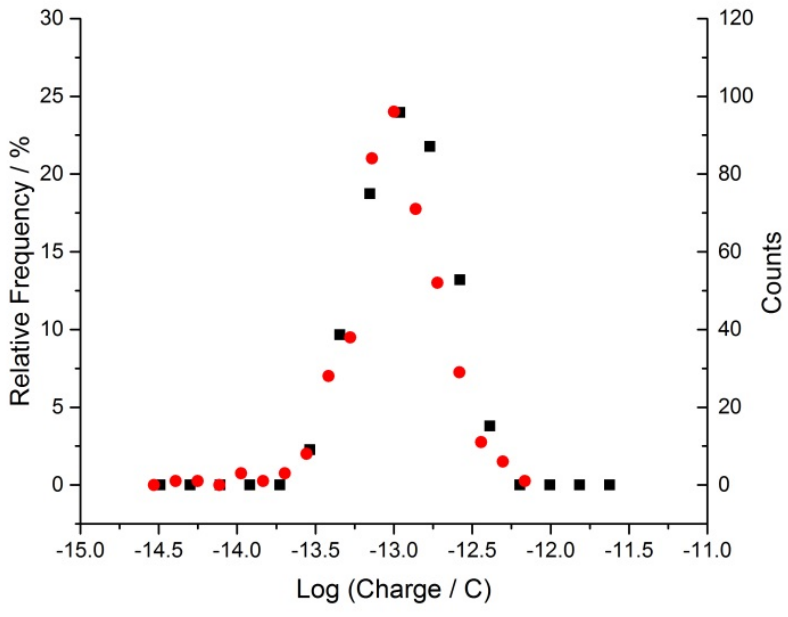

(a)

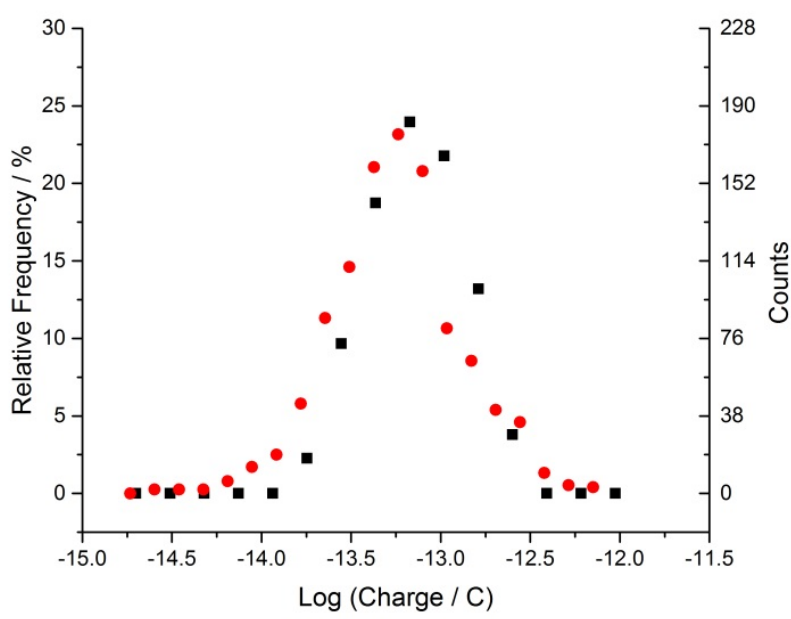

(c)

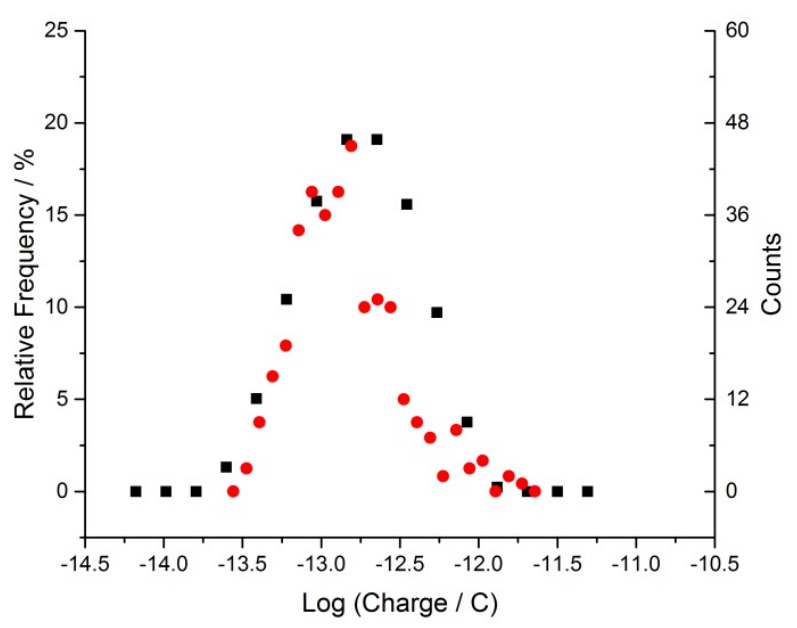

(b)

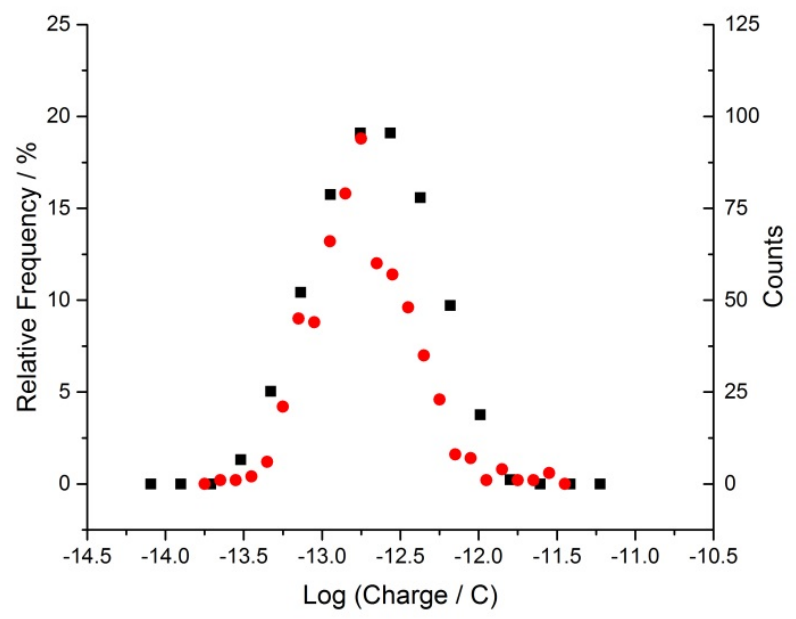

(d)

Figure 6 Histogram showing the log normal distribution of the reductive charge resulting from potassium or sodium ion insertion into single TCNQ nanoparticle calculated from nano-impact experiments (red dots), and the theoretical estimation 
(black dots), assuming the potassium insertion yield $\left(y_{K}\right.$ ) in $\mathrm{K}^{+}$PBS buffer is (a) $49 \%$ for $71 \mathrm{~nm} \mathrm{NPs}$, (b) $36 \%$ for $116 \mathrm{~nm}$ NPs; and sodium insertion yield $\left(y_{N a}\right)$ in $\mathrm{Na}^{+}$PBS buffer is (c) $62 \%$ for $71 \mathrm{~nm} \mathrm{NPs}$, (d) $43 \%$ for $116 \mathrm{~nm} \mathrm{NPs}$.

As can be seen from Figure 4, the resulting charge from potassium or sodium insertion into single nanoparticles increases with particle size, corresponding to current spikes of higher amplitudes $\left(Q_{K 2}>Q_{K 1}, Q_{N a 2}>Q_{N a 1}\right)$. However, the yield of ion insertion into larger TCNQ nanoparticles is less than that into smaller TCNQ nanoparticles $\left(y_{K 2}<y_{K 1}, y_{\mathrm{Na} 2}<y_{\mathrm{Na} 1}\right)$. The sodium insertion occurs a higher extent than potassium insertion under the same conditions $\left(y_{N a 1}>y_{K 1}, y_{N a 2}>y_{K 2}\right)$ possibly due to the smaller radius of sodium ion. For both potassium and sodium insertion, partial rather than complete ion insertion is found which may reflect the formation of a layer of solid TCNQ-A $\mathrm{A}^{+}\left(\mathrm{A}^{+}=\mathrm{K}^{+}\right.$or $\left.\mathrm{Na}^{+}\right)$on the surface of TCNQ nanoparticles, the thickness of which for potassium insertion $t_{K}$ can be estimated to be $7.1 \mathrm{~nm}$ $\left(t_{K 1}\right)$ and $8.0 \mathrm{~nm}\left(t_{K 2}\right)$, respectively for $71 \mathrm{~nm}$ and $116 \mathrm{~nm}$ nanoparticles, and for sodium insertion $t_{N a}$ to be $9.8 \mathrm{~nm}\left(t_{N a 1}\right)$ and $10.0 \mathrm{~nm}\left(t_{N a 2}\right)$ into $71 \mathrm{~nm}$ and $116 \mathrm{~nm}$ TCNQ NPs, according to Equation 2, assuming a perfect core-shell structure.

$$
t=R n p-\sqrt[3]{\frac{3 M(Q i-Q r)}{4 F \pi \rho}}
$$

Equation 2

where $t$ is the thickness of ion insertion of TCNQ nanoparticles, Rnp is the radius of TCNQ nanoparticles, $Q_{i}$ is the ideal charge, $Q_{r}$ is the actual charge resulting from ion insertion, M is the molar mass of TCNQ, $\rho$ is the density of TCNQ and F is the Faraday constant. The parameter $\mathrm{n}$ is the number of electrons transferred for ion insertion of TCNQ $(\mathrm{n}=1)$.

The similar thickness $t\left(t_{K 1} \approx t_{K 2}\right)$ for potassium or sodium insertion $\left(t_{N a 1} \approx t_{N a 2}\right)$ into different sizes of nanoparticles indicates that the formed shell during ion insertion is largely independent on the particle size, while the thicker layer $\left(t_{N a}>t_{K}\right)$ formed by sodium ion 
insertion than potassium ion insertion suggests that the ion insertion thickness is related to the cation type which may be attributed to a higher diffusivity of sodium ions into TCNQ nanoparticles. Here we propose a thin layer limiting mechanism for ion insertion of single TCNQ nanoparticles, where a thin shell of $\mathrm{Na}^{+} / \mathrm{K}^{+} \mathrm{TCNQ}^{-}$is formed during ion insertion and this thin layer of solid TCNQ- $\mathrm{A}^{+}\left(\mathrm{A}^{+}: \mathrm{Na}^{+} / \mathrm{K}^{+}\right)$in turn limits further ion insertion process. Notably, the size and cation dependent ion insertion into microcrystalized TCNQ NPs contracted with the full insertion seen into polymeric nanoparticles ${ }^{14}$ indicates that the structures of substrates into which ion were inserted plays an important role ${ }^{9}$ The strategy we describe here may also provide new quantitative information for the customised design and synthesis of desirable nanostructures. 


\section{Conclusions}

Cation insertion into individual nanoparticles was observed, and the quantitative determination of the extent for cation insertion into single nanoparticles demonstrated. The extent of insertion is inferred to be limited and controlled by the formation of a thin shell of salt, $\mathrm{Na}^{+} / \mathrm{K}^{+} \mathrm{TCNQ}^{-}$formed on the surface of the nanoparticle. Ion insertion thickness $(t)$ of single nanoparticles is found to be not dependent on particle size but cation types, while the extent of ion insertion $(y)$ is found to be quantitatively dependent on both particle size and the cation types. The strategy we report here is general and can be applied to characterise cation/anion insertion into nanoparticles of all types and used to rationalise the molecular design of nanoparticles/nanostructured electrodes for improving ion insertion and subsequently the battery performance. In addition, we believe that the real-time characterisation of ion insertion into single nanoparticles may provide a completely new insight into quantitatively tracking the fast-charge and -discharge of single individual nanoparticles for searching and selecting new nanomaterials for wide energy applications. 


\section{Acknowledgements}

The European Research Council under the European Union's Seventh Framework Programme (ERC Grant Agreement number 320403) is gratefully acknowledged for funding this work. We thank Dr. D Omanović (Center for Marine and Environmental Research Zagreb, Croatia) for developing Signal Counter software for data analysis. 


\section{Reference}

1. Q. Zhang, E. Uchaker, S. L. Candelaria and G. Cao, Chemical Society Reviews, 2013, 42, 31273171.

2. P. Simon and Y. Gogotsi, Nat Mater, 2008, 7, 845-854.

3. C. Rao and K. Biswas, Annual Review of Analytical Chemistry, 2009, 2, 435-462.

4. V. Etacheri, G. A. Seisenbaeva, J. Caruthers, G. Daniel, J.-M. Nedelec, V. G. Kessler and V. G. Pol, Advanced Energy Materials, 2015, 5, doi: 10.1002/aenm.201401289

5. B. Genorio, K. Pirnat, R. Cerc-Korosec, R. Dominko and M. Gaberscek, Angewandte Chemie International Edition, 2010, 49, 7222-7224.

6. N. Yabuuchi, K. Kubota, M. Dahbi and S. Komaba, Chem Rev, 2014, 114, 11636-11682.

7. C. D. Wessells, S. V. Peddada, R. A. Huggins and Y. Cui, Nano Lett, 2011, 11, 5421-5425.

8. S. C. Jung, H. J. Kim, J. W. Choi and Y. K. Han, Nano Lett, 2014, 14, 6559-6563.

9. C. Wang, Y. Xu, Y. Fang, M. Zhou, L. Liang, S. Singh, H. Zhao, A. Schober and Y. Lei, Journal of the American Chemical Society, 2015, 137, 3124-3130.

10. Y.-G. Zhou, N. V. Rees and R. G. Compton, Angewandte Chemie International Edition, 2011, 50, 4219-4221.

11. W. Cheng, X. F. Zhou and R. G. Compton, Angewandte Chemie, 2013, 125, 13218-13220.

12. E. J. Stuart, K. Tschulik, C. Batchelor-McAuley and R. G. Compton, ACS nano, 2014, 8, 76487654

13. W. Cheng and R. G. Compton, TrAC Trends in Analytical Chemistry, 2014, 58, 79-89.

14. X. F. Zhou, W. Cheng and R. G. Compton, Angewandte Chemie International Edition, 2014, 53, 12587-12589.

15. M. Pumera, ACS Nano, 2014, 8, 7555-7558.

16. N. V. Rees, Electrochemistry Communications, 2014, 43, 83-86.

17. X. Xiao and A. J. Bard, Journal of the American Chemical Society, 2007, 129, 9610-9612.

18. X. Xiao, F.-R. F. Fan, J. Zhou and A. J. Bard, Journal of the American Chemical Society, 2008, 130, 16669-16677.

19. A. J. Bard, H. Zhou and S. J. Kwon, Israel Journal of Chemistry, 2010, 50, 267-276.

20. R. Dasari, D. A. Robinson and K. J. Stevenson, Journal of the American Chemical Society, 2013, 135, 570-573.

21. S. E. Fosdick, M. J. Anderson, E. G. Nettleton and R. M. Crooks, Journal of the American Chemical Society, 2013, 135, 5994-5997.

22. W. Cheng, R. G. Compton, Angew. Chem. Int. Ed., 2015, 54, 7082-7085.

23. X. F. Zhou, W. Cheng and R. G. Compton, Nanoscale, 2014, 6, 6873-6878.

24. H. Alves, A. S. Molinari, H. Xie and A. F. Morpurgo, Nat Mater, 2008, 7, 574-580.

25. R. Precht, R. Hausbrand and W. Jaegermann, Physical Chemistry Chemical Physics, 2015, 17, 6588-6596.

26. T. J. Wooster, A. M. Bond and M. J. Honeychurch, Analytical Chemistry, 2003, 75, 586-592.

27. T. J. Wooster and A. M. Bond, Analyst, 2003, 128, 1386-1390.

28. J. Xiao, Z. Yin, Y. Wu, J. Guo, Y. Cheng, H. Li, Y. Huang, Q. Zhang, J. Ma, F. Boey, H. Zhang and Q. Zhang, Small, 2011, 7, 1242-1246.

29. J. Xiao, Z. Yin, H. Li, Q. Zhang, F. Boey, H. Zhang and Q. Zhang, Journal of the American Chemical Society, 2010, 132, 6926-6928.

30. G. Zhao, T. Ishizaka, H. Kasai, H. Oikawa and H. Nakanishi, Chemistry of Materials, 2007, 19, 1901-1905.

31. E. I. Rogers, D. S. Silvester, D. L. Poole, L. Aldous, C. Hardacre and R. G. Compton, J Phys Chem C, 2008, 112, 2729-2735.

32. M. F. Suárez, A. M. Bond and R. G. Compton, J Solid State Electrochem, 1999, 4, 24-33.

33. A. M. Bond, S. Fletcher, F. Marken, S. J. Shaw and P. G. Symons, J. Chem. Soc., Faraday Trans., 1996, 92, 3925-3933. 
34. S. J. Cloake, H. S. Toh, P. T. Lee, C. Salter, C. Johnston and R. G. Compton, Chemistryopen, 2015, 4, 22-26.

35. T. J. Davies, C. E. Banks and R. G. Compton, J Solid State Electr, 2005, 9, 797-808.

36. S. V. Sokolov, C. Batchelor-McAuley, K. Tschulik, S. Fletcher, and R. G. Compton, 2015, Chem. Eur. J.. doi: 10.1002/chem.201500807. 